\title{
Application of a regional approach for hazard mapping at an avalanche site in northern Italy
}

\author{
D. Bocchiola and R. Rosso \\ Politecnico di Milano, L. Da Vinci Square 32, 20133 Milano, Italy \\ Received: 2 May 2007 - Revised: 19 February 2008 - Accepted: 20 February 2008 - Published: 10 April 2008
}

\begin{abstract}
The currently adopted approach to avalanche hazard mapping in northern Italy includes avalanche dynamic modelling, coupled with statistical analysis of snow depth at avalanche start. The 30-years and 300-years return period avalanches at a given site are modelled and their run out zone and pressure are evaluated. The snow depth in the avalanche release zone is assumed to coincide with the three days snow fall depth $\mathrm{H}_{72}$ featuring a return period of 30 years and 300 years, respectively. In the Italian alps only short series of observed snow depth are available, covering a period of 20 years or so, thus requiring a regional approach, or index value approach for the purpose of high return period quantile estimation. Based of former studies, here we apply the index value approach developed for the Lombardia region, in northern Italy, for hazard mapping in a particular avalanche site. A dynamic avalanche model is tuned using the runout data for two major observed avalanche events. Then, the 30years and 300-years runout zone and dynamic pressure are calculated. It is then shown that the obtained hazard maps are more accurate than those obtained using the evaluation of $\mathrm{H}_{72}$ as deduced from distribution fitting in a single site.
\end{abstract}

\section{Introduction}

The Alpine and pre-Alpine area of Lombardia region, in northern Italy, is characterized by relevant tourism during winter and features many ski resort areas. Every year, several avalanches occur therein, and in the period from 1990 to 2000 at least 7200 avalanche events were mapped, with at least 215 casualties (Regione Lombardia, Regional Avalanches Information System, SIRVAL, 2002), thus claiming for reliable avalanche hazard management and land use planning (Barbolini et al., 2003; Ancey et al., 2004). The

Correspondence to: D. Bocchiola

(daniele.bocchiola@polimi.it) current approaches to avalanche hazard mapping include avalanche dynamic modelling (e.g. Christen et al., 2002; Ancey et al., 2004) coupled with statistical analysis of snow depth at avalanche start (Barbolini et al., 2002; Bocchiola et al., 2006). In avalanche hazard mapping exercise, the $T$ years return period avalanches at a given site are computed and their run out zone and pressure are evaluated. The snow depth at release is often assumed to coincide with the snow depth precipitation in the three days before the event, or three days snow fall depth, $H_{72}$ (Salm et al., 1990; Ancey et al., 2004). The Swiss procedure (hereon $S p$, e.g. Salm et al., 1990), also used as a reference in Italy (e.g. Barbolini et al., 2003), provides mapping criteria for dense snow avalanches requiring as an input for each avalanche site the evaluation of the $T$-years value of $H_{72}$ for $T=30$ and $T=300$, at least. The statistical estimation of the $T$-years quantiles of $H_{72}$ is carried out by distribution fitting of the single site maximum annual observed values of $\mathrm{H}_{72}$. According to the theory of extreme values (e.g. Kottegoda and Rosso, 1997; De Michele and Rosso, 2001) to provide reliable estimates of the $T$-years quantiles using empirical distribution fitting, a least number of observations is required, in the order of $n_{\mathrm{obs}}=T / 2$. For $T=300$ years, this amounts to about 150 years of sampled data. In the Italian alps, unless for a very few cases, only short series of observed snow depth are available, covering a period of 20 years or so (e.g. Bocchiola and Rosso, 2007). Bocchiola et al. (2006) have shown that the lack of observed data for distribution fitting of extreme values of $\mathrm{H}_{72}$ can be overcome by using the index value approach. This implies that values of a hydrological variable that are scaled, i.e. divided by an index value have identical frequency distributions across all sites within a given homogenous area, or region (see e.g. Bocchiola et al., 2006). Bocchiola et al. (2006) and Bocchiola and Rosso (2007) have shown that the considered region is homogeneous with respect to the distribution of the greatest annual value of $H_{72}$ and of the daily snow fall, thus making suitable the regional approach. Here, the authors

Published by Copernicus Publications on behalf of the European Geosciences Union. 


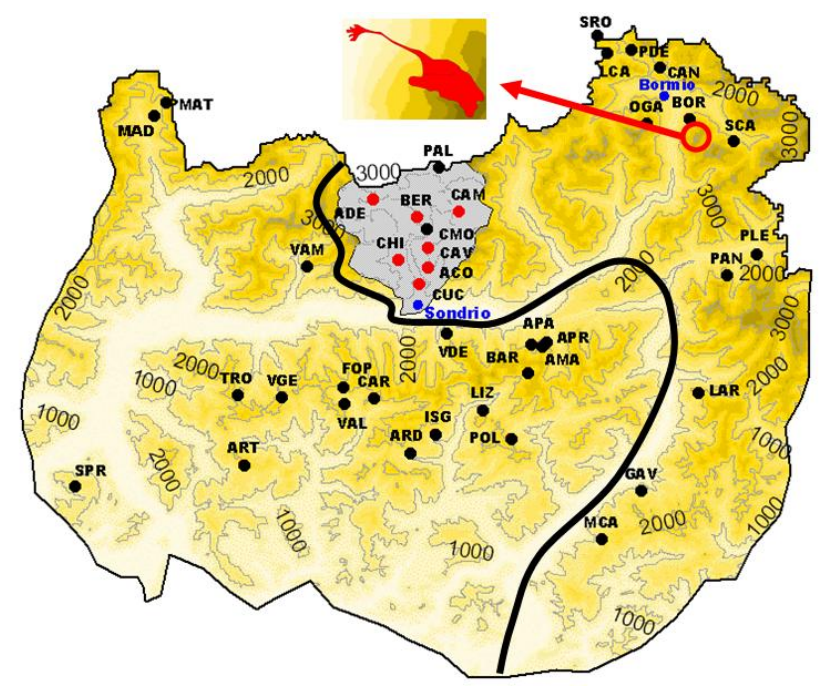

Fig. 1. Case study area. Light dots are ARPA stations, dark dots are AINEVA stations. The dark area is Val Malenco. The black line divides the subregions S-W and N-E for index value assessment. The Vallecetta mountain avalanche site is indicated.

adopt the regional approach to provide hazard mapping for a particular avalanche site in the considered region. This is the Vallecetta avalanche, endangering the town of Bormio and the roadway on the river Adda valley. First a dynamic model (AVAL-1D ${ }^{\circledR}$, Christen et al., 2002) is calibrated for the considered site and validated against data from two (extreme) historical avalanche events. Then, the regionally estimated snow depths are used as an input to the model for hazard mapping according to the $S p$. A comparison is then carried out with the hazard maps as deduced from single site evaluation of the statistical distribution of $H_{72}$. An analysis is then carried out to evaluate the range of uncertainty of the hazard maps due to the uncertainty in the snow depth input.

\section{Regional approach to frequency estimation of $\mathrm{H}_{72}$}

\subsection{Study area and available data base}

The study area (Fig. 1) covers the mountainous area of the Lombardia region, in the central Alpine and pre-Alpine area. There, 40 snow depth measurement stations are present, mainly adopted for avalanche warning purposes, property of the Interregional Association for Snow and Avalanches (AINEVA, 33 stations), located at the Snow and Meteorological Center of Lombardia Region in Bormio city (see Fig. 1b) and of the Regional Agency for the Protection of the Environment (ARPA) of the Lombardia region (7 Stations), located in Sondrio city (see Fig. 1b). The altitude of the stations ranges from the $660 \mathrm{~m}$ a.s.l. of the CUC station to the $2675 \mathrm{~m}$ a.s.l. of LCA station. The reader is referred to Boc- chiola et al. (2006) and Bocchiola and Rosso (2007) for detailed description of the data base.

\subsection{Regional estimation of $\mathrm{H}_{72}$}

Bocchiola et al. (2006), using proper statistical tests, showed that the considered region is homogeneous in terms of snow precipitation and therefore the index value approach can be reliably adopted for the three days snow depth quantiles estimation. According to the index value approach, values of a snow depth observed at a specific site $i$ that are scaled, i.e. divided by an index value, have identical frequency distributions across all the sites within the homogenous area. The index value is usually estimated by the single site sample average, at the specific site $i$

$\mu_{H_{72} i}=\frac{1}{Y_{i}} \sum_{y=1}^{Y_{i}} H_{72 i, y}$,

where $Y_{i}$ is the number of years of observation and the suffix $y$ indicates the $y$ th year. The related standard error of estimation is

$\sigma_{\mu H_{72} i}=\frac{\sigma_{H_{72} i}}{\sqrt{Y_{i}}}$,

with $\sigma_{H_{72} i}$ sample standard deviation of $H_{72}$ at the specific site $i$. The scaled value of $H_{72}$ at each specific site $i$ is therefore defined as

$H_{72 i}^{*}=\frac{H_{72 i}}{\mu_{H_{72} i}} \approx F(1 ; \ldots)$.

The symbol $F$ indicates the regional cumulated probability distribution of $H_{72}^{*}$, valid at each site inside the homogenous region. The average of $H_{72 i}^{*}$ is obviously 1 and the remaining moments need to be estimated from data. Bocchiola et al. (2006) used empirical distribution fitting against the samples of $H_{72 i}^{*}$ from the whole region (609 values) to identify the frequency distribution $F$. This is well accommodated using a General Extreme Value (GEV) distribution. The GEV quantiles featuring $T$-years return period are evaluated as

$H_{72}^{*}(T)=\varepsilon_{p}+\frac{\alpha_{p}}{k_{p}}\left(1-\exp \left(-k_{p} y_{T}\right)\right)$,

with $y_{T}$ Gumbel variable, $y_{T}=-\ln (-\ln ((T-1) / T))$. The parameters of the considered distribution, $\varepsilon_{p}=0.785$, location $\alpha_{p}=0.370$, scale and $k_{p}=-0.005$, shape, are estimated according to the L-moments approach (e.g. Kottegoda and Rosso, 1997). Also, the confidence limits of a given quantile can be evaluated as $H_{72}^{*}(T)=H_{72}^{*}(T) \pm \Phi_{\alpha} \sigma_{H_{72} *}(T)$, where $\Phi_{\alpha}$ is the $1-\alpha / 2$ quantile of standard Normal distribution, N.ST $(0 ; 1)$ and $\sigma_{H_{72} *}(T)$ is the standard deviation of the estimated value of $H_{72}^{*}(T)$, calculated as (De Michele and Rosso, 2001)

$\sigma_{H_{72 *} *}(T)=\left[\left(\frac{\alpha_{p}^{2}}{n_{\text {tot }}}\right) \exp \left(y_{T} \exp \left(-1.823 k_{p}-0.165\right)\right)\right]^{0.5}$ 
The value of $\sigma_{H_{72} *}(T)$ depends for the regional case on the whole sample size $n_{\text {tot }}$ (i.e. 609 values). When single site distribution fitting is carried out, Eq. (5) still holds, provided $n_{\text {tot }}$ is changed with the number of years of observations at the single site, $Y_{i}$. The uncertainty of the $T$-years single site quantile estimation, of direct interest in avalanche hazard mapping, is calculated as follows (see Bocchiola et al., 2006)

$\sigma_{T i}=\sqrt{\sigma_{\mu H_{72} i}^{2} \sigma_{H_{72} *}^{2}+\sigma_{H_{72} *}^{2} \mu_{H_{72} i}^{2}+\sigma_{\mu H_{72} i}^{2} H_{72}^{* 2}}$,

Notice that $\sigma_{\mu H_{72} i}$ always depends on the number of observed years, $Y_{i}$, while the value of $\sigma_{H_{72} *}(T)$ depends for regional distribution fitting on the whole sample size $n_{\text {tot }}$ (i.e. 609 values here) and, for single site distribution fitting, on the number of sampled years, $Y_{i}$. Bocchiola et al. (2006) showed that the value of $\sigma_{T i}$ is considerably smaller for the regional case than for the single site case, particularly for 300-years return period (see Fig. 6 therein). In Fig. 2, it is shown for illustrative purposes the case of the BOR station, the closest one to the Vallecetta avalanche site (see Fig. 1). Notice the very high uncertainty in the single site quantile estimation for considerable return periods, as compared with the regional approach.

\section{Hazard mapping at an avalanche site: the Vallecetta Mountain}

\subsection{Introduction and methodology}

The regional approach is used to provide hazard maps for a particular avalanche site in the alpine area of Lombardia region, the Vallecetta mountain (Fig. 3), situated in the village of Valdisotto, south of Bormio city. The avalanche track is situated in the west side of the Vallecetta mountain, left side of Adda river valley. The release area of the avalanche is in a wide amphitheatre placed above $2400 \mathrm{~m}$ a.s.l. (see Fig. 3). The narrow Vallecetta channel starts at about $2100 \mathrm{~m}$ a.s.l. and it almost runs straight in north-west direction. The channel slope is considerably high, ranging from about $40^{\circ}$ in the initial part, and reaching about $30^{\circ}$ in the final part. Where the mountain toe is reached, at about 1300 m a.s.l., the channel spreads into a vast, more gently sloping alluvial fan and the avalanche track bends towards left, taking west direction and reaching the deposition zone. More than twenty avalanche events of increasing magnitude occurred at this avalanche site ever since 1886, when the first recorded event is reported. Thereafter, avalanche events have been sporadically mapped by the Rangers (Guardia Forestale) of Sondrio city and, only since 1981, a full avalanche cadastre is available. Two events of considerable magnitude occurred in May 1983. On 1 May the avalanche reached the alluvial fan and stopped at $1174 \mathrm{~m}$ a.s.l. and the deposited snow blanket paved the way for a second avalanche, occurring on 16

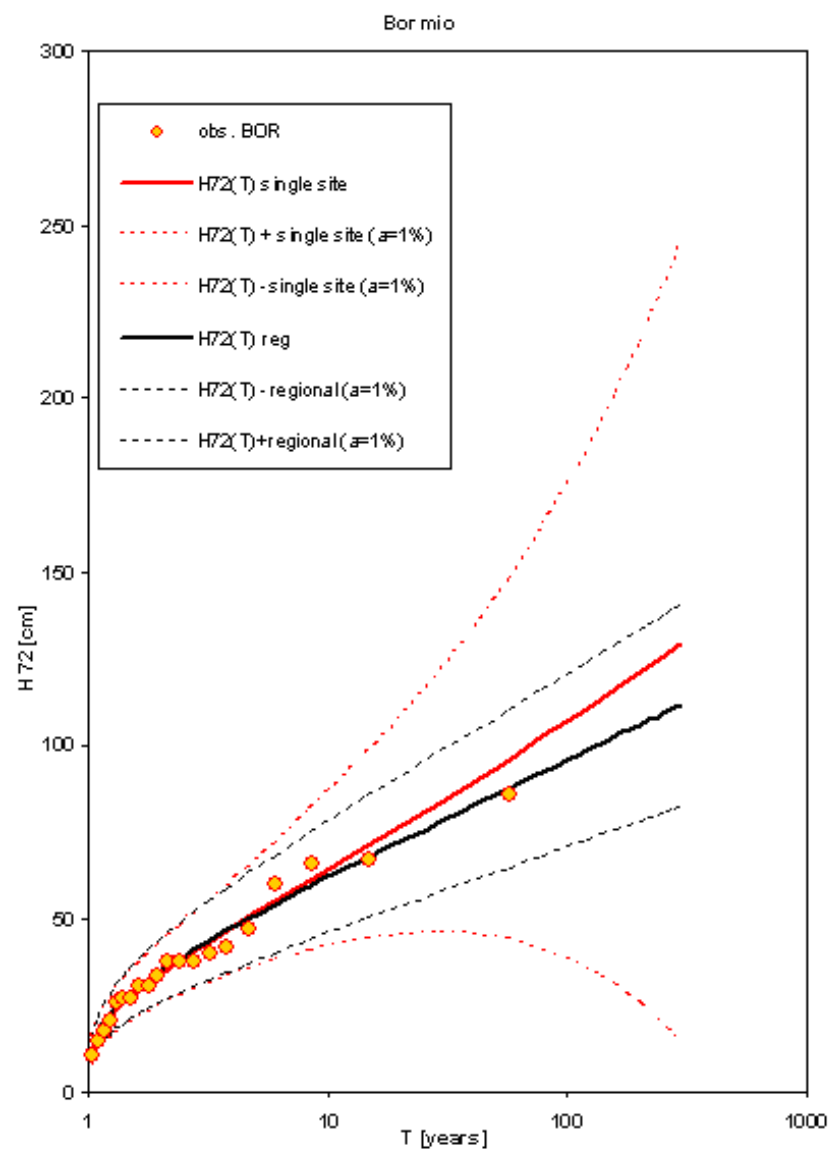

Fig. 2. Regional and local estimation of $T$-years quantiles of $H_{72}$ and related uncertainty (1\% confidence range) for the Bormio station.

May, reaching the Adda river (longest path ever) and occupying the state road SS 38 in the valley below for $500 \mathrm{~m}$, also causing one casualty. More recently, on 12 March 2004, a snow avalanche in the channel reaching $2300 \mathrm{~m}$ a.s.l. killed a cross country skier. Because the avalanche track considerably affects the city of Bormio and the valley infrastructures, also influencing land use planning, reliable hazard mapping is necessary. Hazard mapping for dense snow avalanches, of interest here, is carried out with reference to the $S p$. They are based on the definition of a more dangerous red zone (impact pressure $P r \geq 30 \mathrm{kPa}$ and $T \leq 300$ years, or $P r \leq 30 \mathrm{kPa}$ and $T \leq 30$ years) and of a less dangerous blue zone (impact pressure $\operatorname{Pr} \leq 30 \mathrm{kPa}$ and $30 \leq T \leq 300$ years). Two main tools are necessary. The first is a numerical model, allowing dynamic simulation of a flowing avalanche, which is shown to be reliable by comparison against some observed avalanche events. The software AVAL-1D is used here, developed at the Swiss Federal Institute for Snow and Avalanches Research (SLF), in Davos. Because the model is suitable for extreme (i.e. of considerable magnitude) avalanche events, the two greatest observed events (i.e. on 1 and 16 May 1983) 


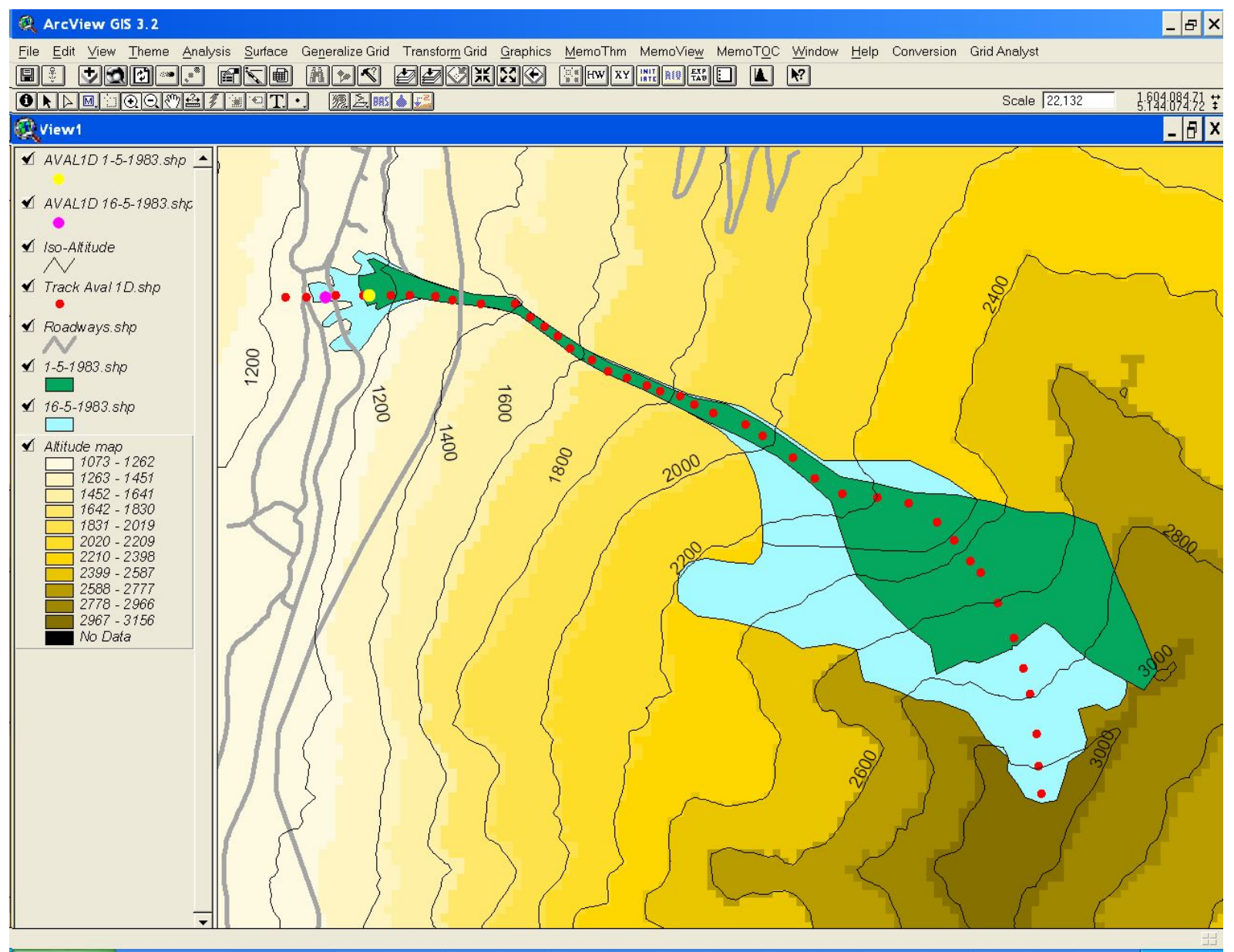

Fig. 3. Vallecetta avalanche site. Mapped release and runout of the two largest observed events on 1 and 16 May 1983 . Red dots show the track chosen for dynamic simulation with AVAL-1D. Also, runout mapped using AVAL-1D is reported for the two events.

are selected from the available avalanche cadastre to test the model, which is thereafter used for avalanche simulation. The necessary data base is therefore provided by the characteristic data of the avalanches. The second tool is the input snow depth at release, which is defined according to a statistical distribution. Here, the regional distribution developed by Bocchiola et al. (2006) is used. The necessary data base is given by the daily snow depth measurements reported in Sect. 2.1.

\subsection{Validation of AVAL-1D}

In Fig. 3, a view of the release and runout zone for the two considered avalanche events is given, as deduced from avalanche cadastre data, kindly made available by the Rangers of Sondrio city. The main features of the observed events are reported in Table 1. The greatest avalanche on 16 May 1983 started at altitude $A_{0}=3140$ m a.s.l. (greatest altitude), with an estimated fracture depth $H_{S}=1.3 \mathrm{~m}$ and an estimated fracture length $L_{0}=1254 \mathrm{~m}$ and width $W_{0}=1300 \mathrm{~m}$, for a volume at release $V_{0}$ of more than $2 \times 10^{6} \mathrm{~m}^{3}$. It reached the lowest altitude $A_{R}=1144 \mathrm{~m}$ a.s.l., at an estimated run out distance $R=5172 \mathrm{~m}$.

First, to carry out a 1-D simulation of the avalanche, a representative profile was chosen. This was done after a preliminary analysis, taking the avalanche track leading to the greatest observed runout for both the observed events, shown on Fig. 3. The geometric variables of the avalanches were fed to the model. Then, the model parameters were set up according to the model guidelines (Christen et al., 2002). These are the dry and turbulent friction parameters, $\mu$ and $\xi$, both depending on avalanche size, local topography (i.e. open hill slope, channel or gully), range of altitude and approximate return period of the avalanche (30 or 300 ). In view of the considerable magnitude of the two events here considered (the greatest observed since 1886), a return period of 300 years is assumed for model estimation. The results of the simulation are reported in Table 1. The avalanche events seem to be well described by the model in terms of runout distance. In Fig. 4, the results of the model are shown 
Table 1. Vallecetta avalanche events on 1 and 16 May 1983 and Validation of Aval-1D. Symbols explained in text. Symbol // indicates an input value to the model. $E_{R}$ is the percentage error in runout distance evaluation by the model.

\begin{tabular}{lcccccccc}
\hline Source & $A_{0}$ [m a.s.1.] & $A_{R}$ [m a.s.1.] & $R[\mathrm{~m}]$ & $E_{R}[\%]$ & $H_{S}[\mathrm{~m}]$ & $W_{0}[\mathrm{~m}]$ & $L_{0}[\mathrm{~m}]$ & $V_{0}\left[\mathrm{~m}^{3}\right]$ \\
\hline Observed 1 May 1983 & 2950 & 1174 & 4877 & - & 0.9 & 800 & 1110 & $7.99 \mathrm{E}^{5}$ \\
AVAL-1D 1 May 1983 & $/ /$ & 1176 & 4838 & $-0.5 \%$ & $/ /$ & $/ /$ & $/ /$ & $/ /$ \\
Observed 16May 1983 & 3140 & 1144 & 5172 & - & 1.3 & 1300 & 1254 & $2.118 \mathrm{E}^{6}$ \\
AVAL-1D 16 May 1983 & $/ /$ & 1149 & 5110 & $-1.1 \%$ & $/ /$ & $/ /$ & $/ /$ & $/ /$ \\
\hline
\end{tabular}

in terms of maximum evaluated snow depth for the 16 May event. Also, the adopted values of the dry friction parameter $\mu$ are given, particularly affecting runout distance evaluation (Christen et al., 2002). The values of the turbulent friction parameter $\xi$ in the four considered zones are $\xi=2500,1800$, 1500 and 2000, respectively. In view of the reasonably good results obtained with the proposed setup of the model, the authors feel confident in proceeding to hazard mapping for the Vallecetta site.

\subsection{Evaluation of $\mu_{H_{72}}$ for ungauged sites}

For hazard mapping, evaluation of $H_{72}$ needs to be carried out in the release zone of the avalanche, where no snow gage is available to calculate the index value. When evaluation of $\mu_{H_{72}}$ is required in an ungauged site, its estimation can be carried out based on altitude. In fact, altitude $A$ is possibly the factor that mostly influences the distribution of snow fall in space (see e.g. Barbolini et al., 2002, Bocchiola and Rosso, 2007). The $S p$ suggests an increase of $H_{72}$ (for $T=300$ years) of $5 \mathrm{~cm}$ with $100 \mathrm{~m}$ in altitude (Salm et al., 1990). Frequently, the index value can be estimated using a linear regression against altitude, i.e.

$\hat{\mu}_{H_{72} \text { un }}=c \cdot A_{u n}+\mu_{0}$,

with $A_{\text {un }}$ altitude of the ungauged site and $\mu_{0}$ intercept for $A=0$. Its standard deviation can be evaluated as

$\hat{\sigma}_{\mu H_{72} u n}=\hat{\sigma}_{E\left[H_{72}\right]} \cdot \sqrt{1-R^{2}}$,

with $\hat{\sigma}_{E\left[H_{72}\right]}$ observed (sample) standard deviation of the index value for the sites used to evaluate the altitude to depth equation and $R^{2}$ determination coefficient of the equation itself. The evaluation of snow depth-altitude relationships for the considered region is carried out as follows. First, an analysis is made aimed to evidence regional factors into the distribution of the index value $\mu_{H_{72}}$. In fact, while the analysis of the dimensionless quantiles of $H_{72}$ indicates homogeneity of the region, it is not a priori known whether the same homogeneity is observed as far as the distribution of $\mu_{\mathrm{H}_{72}}$ in space is considered. This occurs because the value of $\mu_{H_{72}}$ interprets the local variability of the processes influencing the average magnitude of the observed values of three days snow depth. This issue is often observed, for instance, in

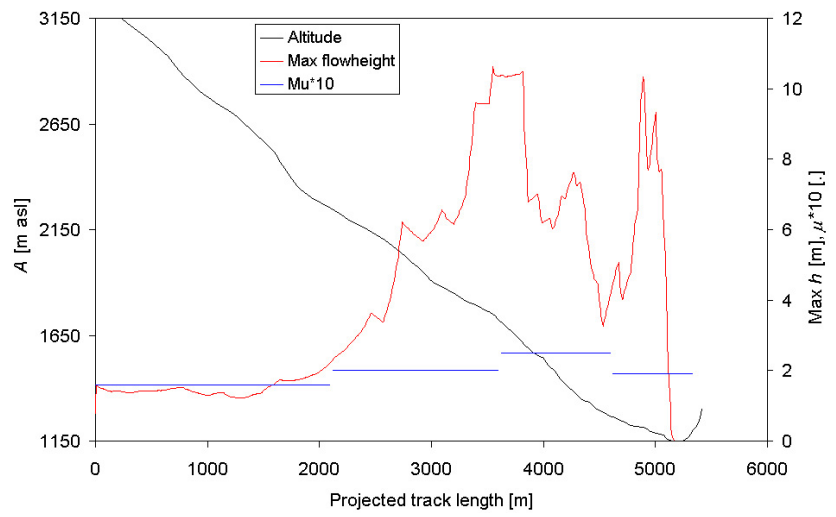

Fig. 4. Vallecetta avalanche site. Simulation with AVAL-1D of the greatest observed event on 16 May 1983. Runout zone and maximum snow depth are reported in the top chart. The dry friction parameter $\mu$ is reported in the lower chart, and varies with avalanche volume, topography, altitude and expected return period. The values of the turbulent friction parameter $\xi$ in the four considered zones are $\xi=2500,1800,1500$ and 2000 , respectively.

the field of flood hydrology, where regional homogeneity of the growth curve does not necessarily imply homogeneity of the index flood values (i.e., their relationship with geomorphologic attributes, particularly with drainage area), thus requiring a further step in the regionalization procedure ("hierarchic approach" to regionalization, see e.g. Gabriele and Arnell, 1991). In short, this step consists of testing the presence of sub-regions of the greater homogenous region, where the dependence of $\mu_{H_{72}}$ with altitude $A$ is homogenous. This is accomplished using some statistical procedures, resulting into a reasonable zoning (i.e. avoiding unreasonable leopard skin pattern). Here, based on the present literature, statistical grouping techniques are adopted, including Principal Components Analysis (PCA), Factor Analysis (FA) and Cluster Analysis (CA) (e.g. Baeriswyl and Rebetez, 1997), currently used for regionalization of snow properties. This was done for 31 stations out of the 40 stations considered here, featuring at least $Y_{i}=10$ (see Bocchiola et al., 2006), for reliability of the procedure. Several attempts were carried out, using PCA, FA (also using Varimax rotation) and also CA of the resulting loadings (e.g. Baeriswyl and Rebetez, 1997). 


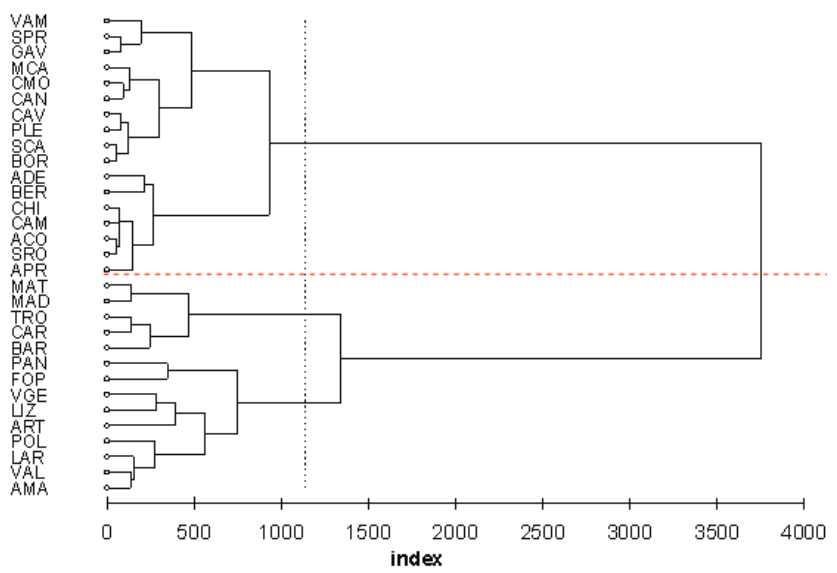

Fig. 5. Cluster Analysis dendrogram, CA of the observed values of $H_{72}$ (see e.g. Kottegoda and Rosso, 1997). The red dashed line indicates the two final sub regions.

However, the most reasonable results were obtained by $\mathrm{CA}$ of the observed values of $\mathrm{H}_{72}$. Particularly, using direct CA, three main groups were identified (Fig. 5). However, the comparison with the scatter plots of $\mu_{H_{72}}$ against $A$, the definition of which is the objective of the procedure, showed that the two smallest groups, presenting contiguity on the dendrogram, could be in fact joint, so leading to more consistent patterns (Fig. 6). Contrarily to the case of L-moments of the dimensionless quantiles of $\mathrm{H}_{72}$, where no spatial patterns could be observed (in Bocchiola et al., 2006), here a more organized spatial pattern was observed, i.e. one with quite clear separation, without isolated spots. A few adjustments were necessary, only based on geographical continuity, but with no change in the general observed patterns. It is evident that the two regions so obtained roughly indicate a difference of the snow fall process from south-west to north-east. The first sub-region covers the Orobie Pre-alps and the western part of the Retiche Alps. The second sub-region covers the central to north-eastern part of the Retiche Alps. The Oglio river valley (south-east in Fig. 1) is split in two parts and the boundary is approximately drawn following the river valley. This could be due to different aspects of the eastern and western slopes. Henceforth, the two regions will be referred to as S-W and $\mathrm{N}-\mathrm{E}$. The boundary between the two regions has been drawn by including the related gauges and by following as much as possible the watersheds boundaries and the river valleys, providing natural divides. In Fig. 6, the altitude-depth relationships are given, showing for the region S-W higher snow depths than for the region N-E. This looks reasonable, considering the climatic conditions of the area and also some former results by the authors (Bocchiola et al., 2006; Bocchiola and Rosso, 2007). This is consistent with the meteorological patterns leading to snow precipitation in the considered area, with intrusion of air masses, draining moisture from the Como lake (on the left part in Fig. 1) and then moving

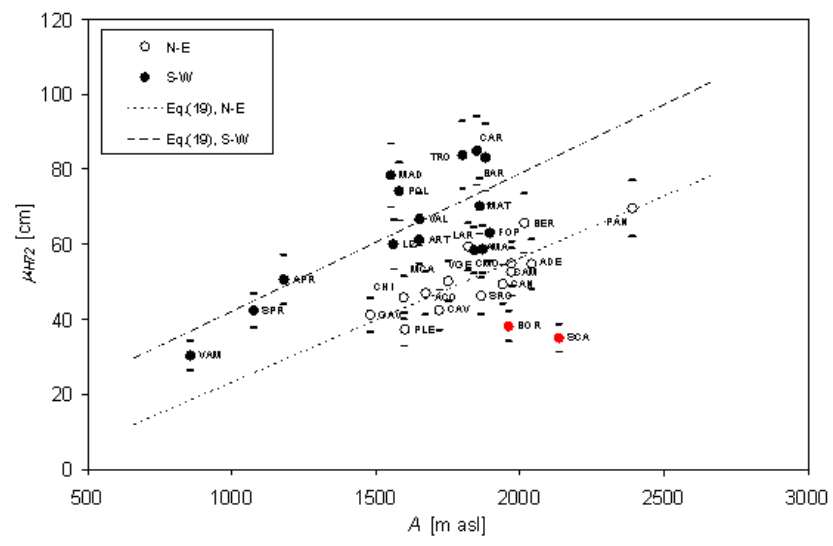

Fig. 6. Altitude to average depth $\mu_{H_{72}}$ relationships for the two regions S-W and N-E. Sigma bounds are reported for the single site estimates of $\mu_{H_{72}}$.

from S-W to N-E, so providing decreased snow precipitation in the northern area. The regression equations for the two regions are reported in Table 2. Notice that the slope $c$ provides for region $\mathrm{S}-\mathrm{W}$ an increase of the index value of about $4 \mathrm{~cm}$ $(c=3.7)$ in $100 \mathrm{~m}$, while in region N-E a somewhat smaller increase is noticed, of $c=3.3 \mathrm{~cm}$ in $100 \mathrm{~m}$. For instance, this seems consistent with the findings in Barbolini et al., 2002 $(c=3.8 \mathrm{~cm} / 100 \mathrm{~m})$ for some snow gauges in the Mallero river valley (here, in region N-E, grey area in Fig. 1). Notice that in the scatter plot in Fig. 6 a degree of superposition is present of the data points related to the two regions, particularly for the two stations APR and LAR (APA was not used in the procedure because $Y_{i}<10$ ). The definition of the boundaries in that area is uncertain and more information would be required therein. The two stations BOR and, to a greater extent, SCA, have been found to provide a somewhat different behavior from the remaining gauges. This is probably the result of some local (micro) climatic condition and should be taken into account when evaluating the values of $\mu_{H_{72}}$ for the Vallecetta area.

\subsection{Estimation of $\mathrm{H}_{72}(T)$ for the Vallecetta avalanche site}

Here, the design values of $H_{72}(T)$ featuring $T=30$ and $T=300$ years are estimated in the release area of the Vallecetta avalanche, which is situated at an average altitude $\bar{A}_{0}=3000 \mathrm{~m}$ a.s.l. The gauged station closest to the Vallecetta avalanche release zone is the BOR station (see Fig. 1). Again, notice from Fig. 6 that in the BOR area considerably low values of $\mu_{H_{72}}$ seem to occur as compared to the remaining part of the N-E region, as also witnessed by the observed values of $\mu_{H_{72}}$ in SCA station. Therefore, we evaluate $\mu_{H_{72}}$ in the release area by increasing its observed value on BOR station by an amount proportional to the rate of increase with altitude observed in the $\mathrm{N}-\mathrm{E}$ region

$\hat{\mu}_{H_{72} u n}=\hat{\mu}_{H_{72} g a}+c \cdot\left(A_{u n}-A_{g a}\right)$, 
Table 2. Relationship between $\mu_{H_{72}}$ and $A$ in the regions S-W and N-E.

\begin{tabular}{cccccccccc}
\hline Region & Ns [.] & $c[\mathrm{~cm} / 100 \mathrm{~m}]$ & $\mu_{0}[\mathrm{~cm}]$ & $R^{2}[]$. & $p[]$. & $E\left[\mu_{H_{72}}\right][\mathrm{cm}]$ & $\hat{\sigma}_{E\left[H_{72}\right]}[\mathrm{cm}]$ & $\sigma_{c}[\mathrm{~cm} / \mathrm{m}]$ & $\hat{\sigma}_{\mu H_{72} \text { un }}[\mathrm{cm}]$ \\
\hline S-W & 15 & 3.7 & 5.40 & 0.59 & $10^{-3}$ & 64.41 & 15.63 & 0.009 & 10.07 \\
N-E & 14 & 3.3 & -9.87 & 0.72 & $10^{-4}$ & 51.18 & 9.15 & 0.006 & 4.85 \\
\hline
\end{tabular}

Table 3. Estimated values of $H_{72}(T)$ for the Vallecetta avalanche release area.

\begin{tabular}{|c|c|c|c|c|c|c|c|c|}
\hline App & $\begin{array}{c}T \\
\text { [years] }\end{array}$ & $\begin{array}{c}\bar{A}_{0} \\
\text { [m a.s.l.] }\end{array}$ & $\begin{array}{l}\mu_{H_{72}} \\
{[\mathrm{~cm}]}\end{array}$ & $\begin{array}{c}H_{72}(T) \\
{[\mathrm{cm}]}\end{array}$ & $\begin{array}{c}\hat{\sigma}_{\mu H_{72}} \text { un } \\
{[\mathrm{cm}]}\end{array}$ & $\begin{array}{c}\hat{\sigma}_{H_{72} \text { un }} \\
{[\mathrm{cm}]}\end{array}$ & $\begin{array}{c}H_{72}(T)+(1 \%) \\
{[\mathrm{cm}]}\end{array}$ & $\begin{array}{c}H_{72}(T)-(1 \%) \\
{[\mathrm{cm}]}\end{array}$ \\
\hline Reg & 300 & 3000 & 72.5 & 212.0 & 4.3 & 17.7 & 257.5 & 166.4 \\
\hline Reg & 30 & 3000 & 72.5 & 148.4 & 4.3 & 9.9 & 174.0 & 122.9 \\
\hline Site & 300 & 3000 & - & 181.3 & - & 49.8 & 309.5 & 53.1 \\
\hline Site & 30 & 3000 & - & 135.7 & - & 16.4 & 177.9 & 93.5 \\
\hline
\end{tabular}

with $A_{g a}$ altitude of the gauged site (here, BOR station). The estimation variance is

$\hat{\sigma}_{\mu H_{72} u n}=\sqrt{\hat{\sigma}_{\mu H_{72} g a}^{2}+\hat{\sigma}_{c}^{2} \cdot\left(A_{u n}-A_{g a}\right)^{2}}$.

The related value of $\mu_{H_{72}}$ is reported in Table 3. This is then multiplied by the growth factor $H_{72}^{*}(T)$ calculated as in Eq. (4) for $T=30$ years and $T=300$ years. The so obtained values are also reported in Table 3. Also, the same calculation is carried out by considering the estimated value of the quantile $H_{72}(T)$ obtained by using the single site approach. This is obtained by the presently adopted approach in avalanche hazard mapping according to the $S p$, i.e. taking the estimated value of $H_{72}(T)$ in the closest observed station, i.e. BOR station in this case and then increasing it by $5 \mathrm{~cm}$ every 100 meters in altitude. Notice the considerable difference in the estimated values of $H_{72}(T)$ obtained using the regional approach, as compared to those from the single site approach.

\section{Hazard maps}

\subsection{Regional and single site estimation of $\mathrm{H}_{72}(T)$}

The values of $H_{72 i}(T)$ estimated in Sect. 3.4 are used as an input to AVAL-1D, after proper correction for local slope (e.g. Salm et al., 1990). The model provides calculation of the avalanche volume, the length of the runout zone and the impact pressures (e.g. Barbolini et al., 2002; Ancey et al., 2004), used for the evaluation of the red zone and the blue zone, according to the $S p$. The so obtained zones are shown in Fig. 7 for the chosen avalanche profile, giving the longest avalanche track for fixed snow depth, as verified in a preliminary analysis. To extend each zone to a bi-dimensional chart, a circle is taken with its centre in the starting point of

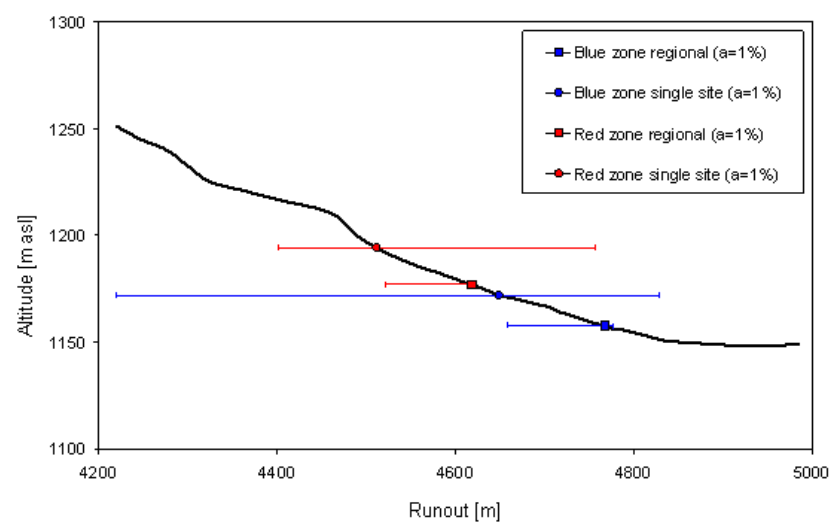

Fig. 7. Vallecetta avalanche site. Sensitivity analysis of avalanche hazard zoning to the input in terms of snow depth at release. Regional and single site case. Notice the considerably smaller uncertainty when the regional approach is used.

the alluvial fan, placed at $1350 \mathrm{~m}$ a.s.l. (Fig. 4) and passing through the corresponding point in Fig. 7. The so obtained zones are reported in Fig. 8a, referenced on a photograph of the Vallecetta avalanche area, showing the presence of inhabited areas at the bottom of the valley, the roadways and the Adda river. Also, the zoning procedure is carried out using the expected values of snow depth calculated by the single site approach. The results are shown in Figs. 7 and 8b. Notice that both the red and blue zones extend much farther when using the regional approach. This stems from the substantially underestimated values of $H_{72}(T)$ obtained by the single site approach (compare Table 3). 


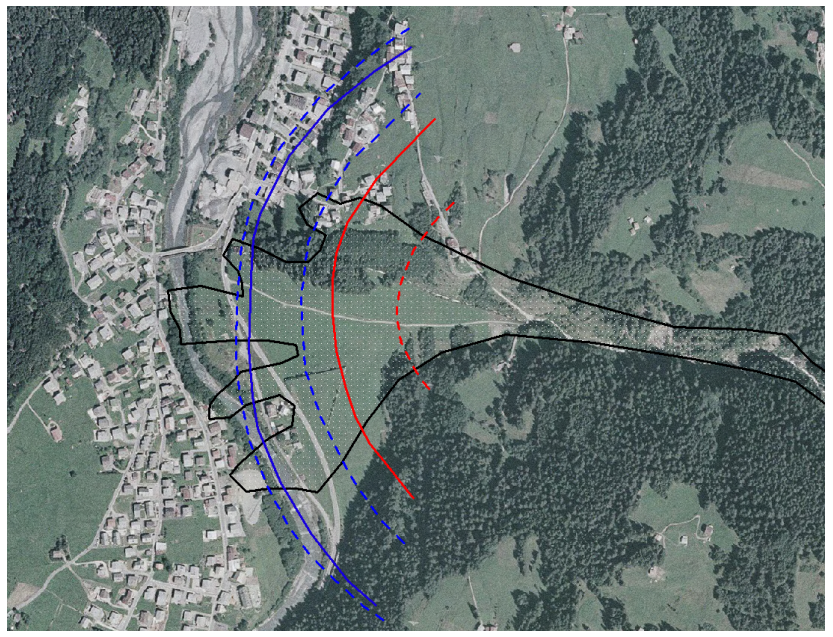

(a)

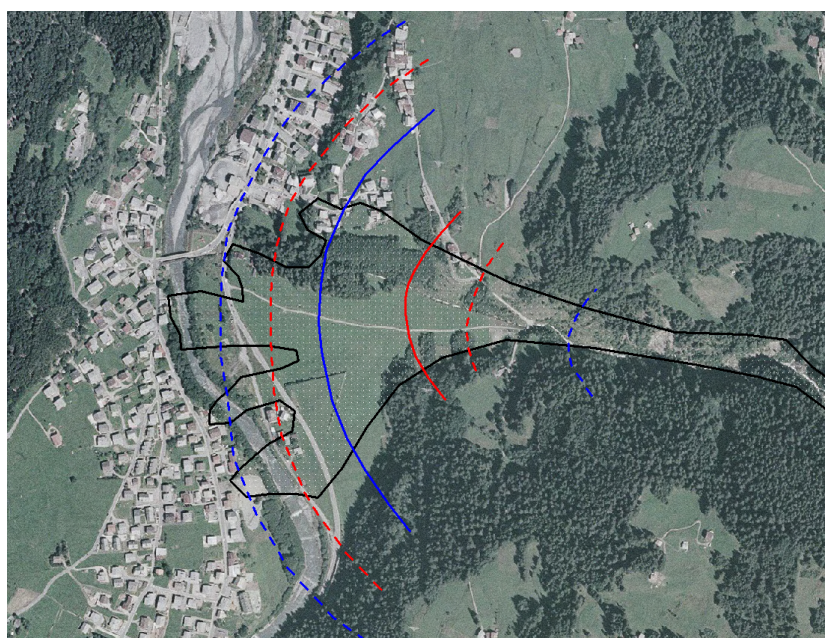

(b)

Fig. 8. Vallecetta avalanche site. Avalanche hazard maps superposed to a photograph of the area. (a) Regional approach. (b) Single site approach. Black line is the mapped deposit event of 16 May 1983.

\subsection{Uncertainty in hazard maps}

The confidence in the red and blue zones is considerably influenced by the uncertainties in the evaluation of the input values of $H_{72 i}(T)$ (Barbolini et al., 2002; Ancey et al., 2004). It seems therefore warranted to make a sensitivity analysis of the hazard maps based on the probabilistic assessment of the distribution of the input value $H_{72 i}(T)$ (e.g. Barbolini et al., 2002, Table II). As far as the GEV distribution is considered, the $T$-years quantile is Normally distributed (e.g. De Michele and Rosso, 2001). Its average is given by the estimated value, $H_{72 i}(T)$, and its standard deviation is given by $\sigma_{T i}$, calculated according to Eq. (6). In Table 3, the values of $\sigma_{T i}$ are reported as obtained using the regional method, together with the corresponding confidence limits, for a confidence level $\alpha=1 \%$. The latter limits indicate the degree of uncertainty obtained when estimating the quantiles of $H_{72 i}(T)$ for considerable return periods (here, for $T=30$ and $T=300$ years). Also, the same values are reported when calculated for the single site approach, i.e. using the observed distribution at BOR station. It is obvious that the confidence limits are considerably smaller when the regional approach is used (as also shown in Fig. 2, valid at BOR station). To obtain a sensitivity analysis of the hazard maps to the uncertainty in snow depth quantile estimates, the red and blue zone are re-evaluated using the estimated values of $H_{72}(T)$ corresponding to the upper and lower confidence limits for $\alpha=1 \%$, shown in Table 3. This analysis can of course be carried out for different levels of confidence. In Fig. 7, the confidence limits of the red and blue zone using the regional approach are shown. Also, they are reported in Fig. 8a. Note that, due to the relatively small variation of $H_{72}(T)$ for $T=30$ years (in Table 3), the model AVAL-1D shows a negligible change in the upper confidence limit of the red zone when using the regional approach. Then, the same analysis is carried out using the confidence limits of $H_{72}(T)$ calculated by the single site approach. The confidence limits of the red and blue zone for the single site approach are reported in Figs. 7 and 8b. It is clear that the single site approach provides unreasonably wide confidence limits as compared to the regional approach. This results into high uncertainty in sketching of avalanche prone areas. In this case, use of the regional approach would result in more certainly defined hazard zones and, therefore, in more reliable land use planning.

\section{Conclusions}

Due to the relative shortness of the snow monitoring data base in the Alpine range of Lombardia region, in central Italian Alps, a regional approach is required for avalanche hazard mapping based on snow depth quantiles. Also, uncertainty in quantiles estimation, which is particularly high in view of the considered return periods, in the order of 300 years or so, must be incorporated. Here it is shown that a regional approach previously developed to model the distribution of the values the three days snow fall depth $\mathrm{H}_{72}$ at different sites can be used to provide an input for avalanche dynamics models. A particular avalanche site is considered, where relevant avalanche events have been observed, endangering the town of Bormio and the nearby ski area. The use of a well known and reliable avalanche dynamics model shows that hazard mapping according to the $S p$ is sensitive to uncertain definition of the input values of the snow depth. Because the regional approach provides estimated values of $\mathrm{H}_{72}$ that are considerably less uncertain than those from single site analysis, currently adopted in avalanche hazard evaluation, the resulting maps can be used with more confidence. The regional approach is valuable, because it provides a tool 


\begin{tabular}{|c|c|}
\hline \multicolumn{2}{|c|}{ Nomenclature } \\
\hline$A$ & Altitude \\
\hline$c$ & $\begin{array}{l}\text { Rate of increase of index value of three day } \\
\text { snow depth with altitude }\end{array}$ \\
\hline$F$ & Theoretical probability distribution of $H_{72}^{*}$ \\
\hline$H_{72}$ & Annual maximum three days snow fall depth \\
\hline$H_{72 i}$ & $\begin{array}{l}\text { Single site }(i) \text { annual maximum three days } \\
\text { snow fall depth }\end{array}$ \\
\hline$H_{72 i}^{*}$ & $H_{72 i}$ scaled by its single site sample average \\
\hline$H_{S}$ & $\begin{array}{l}\text { Observed snow fracture depth at avalanche re- } \\
\text { lease }\end{array}$ \\
\hline$i$ & Site index of snow measuring stations \\
\hline$k_{p}, \varepsilon_{p}, \alpha_{p}$ & $\begin{array}{l}\text { Shape, location and scale parameters of the re- } \\
\text { gional GEV distribution }\end{array}$ \\
\hline$L_{0}$ & Avalanche fracture length at release \\
\hline$n_{\mathrm{obs}}$ & $\begin{array}{l}\text { Number of required observations of } H_{72} \text { to } \\
\text { obtain quantiles with given return period }\end{array}$ \\
\hline$n_{\text {tot }}$ & $\begin{array}{l}\text { Total number of observed values of } H_{72} \text { in the } \\
\text { region }\end{array}$ \\
\hline$R$ & Avalanche runout distance \\
\hline$T$ & Return period in years \\
\hline$V_{0}$ & Avalanche volume at release \\
\hline$W_{0}$ & Avalanche fracture width at release \\
\hline$y$ & Year index \\
\hline$Y_{i}$ & $\begin{array}{l}\text { Number of available years (winter season) of } \\
\text { observation at site } i\end{array}$ \\
\hline$\mu, \xi$ & $\begin{array}{l}\text { Dry and turbulent friction coefficients of } \\
\text { AVAL-1D model }\end{array}$ \\
\hline$\mu_{H_{72} i}$ & $\begin{array}{l}\text { Single site (i) sample average (index value) of } \\
\mathrm{H}_{72}\end{array}$ \\
\hline$\sigma_{H_{72} i}$ & Single site $(i)$ standard deviation of $H_{72}$ \\
\hline$\sigma_{E\left[H_{72}\right]}$ & $\begin{array}{l}\text { Sample standard deviation of } \mu_{H_{72} i} \text { in the } \\
\text { considered snow measurement sites }\end{array}$ \\
\hline$\sigma_{\mu H_{72} i}$ & $\begin{array}{l}\text { Single site }(i) \text { standard deviation of the single } \\
\text { site sample average of } H_{72}\end{array}$ \\
\hline$\sigma_{H_{72} *}$ & $\begin{array}{l}\text { Single site }(i) \text { standard deviation of the esti- } \\
\text { mated values of } H_{72}^{*}(T)\end{array}$ \\
\hline$\sigma_{T i}$ & $\begin{array}{l}\text { Single site }(i) \text { standard deviation of the } T \text { - } \\
\text { years quantile of } H_{72}\end{array}$ \\
\hline
\end{tabular}

valid in the whole considered region, covering the central part of Italian Alps and pre-Alps. It is therefore expected that the use of this approach, coupled with properly validated avalanche dynamic models, could lead to more confident hazard mapping in the whole considered region.
Acknowledgements. The authors kindly acknowledge the personnel of AINEVA, in Bormio, ARPA Lombardia and the Rangers (Guardia Forestale) in Sondrio for providing snow and avalanche data from their data bases. Eng. Michele Medagliani is kindly acknowledged for help in setting up the avalanche data base. Funding for the research presented in this paper was granted by the European Community, through the EU project IRASMOS (EC Contract 018412).

Edited by: P. Lagos

Reviewed by: M. Larsen and M. Klein

\section{References}

Ancey, C., Gervasoni, C., and Meunier, M. :Computing extreme avalanches, Cold Reg. Sci. Technol., 39, 161-180, 2004.

Baeriswyl, P. A. and Rebetez, M.: Regionalization of precipitation in Switzerland by means of principal components analysis, Theor. App. Climatol., 58, 31-41, 1997.

Barbolini, M., Natale, L., and Savi, F.: Effect of release conditions uncertainty on avalanche hazard mapping, Nat. Hazards, 25, 225-244, 2002.

Barbolini, M., Cordola, M., Natale, L., and Tecilla, G.: Hazard mapping and land use regulation in avalanche prone areas: recent developments in Italy, in: Recommendations to deal with snow avalanches in Europe, Ch. 5, edited by: Hervás, J., EUR 20839 EN, JRC, Ispra, 2003.

Bocchiola, D., Medagliani, M., and Rosso, R.: Regional snow depth frequency curves for avalanche hazard mapping in central Italian Alps, Cold Reg. Sci. Technol., 46, 3, 204-221, 2006.

Bocchiola, D. and Rosso, R.: The distribution of daily Snow Water Equivalent in the Central Italian Alps, Adv. Water Resour., 30, 135-147, 2007.

Christen, M. Bartelt, P., and Gruber, U.: An avalanche dynamics program for the practice. Proceedings: International Congress Interpraevent 2002 in the Pacific Rim, 14-18 October, Matsumoto, Japan, 2, 715-725, 2002.

De Michele, C. and Rosso, R.: Uncertainty assessment of regionalized flood frequency estimates, J. Hydrol. Eng., ASCE, 6(6), 453-459, 2001.

Gabriele, S. and Arnell, N.: A hierarchic approach to regional flood frequency analysis, Wat. Resour. Res., 27, 6, 1281-1289, 1991.

Kottegoda, N. and Rosso, R.: Statistics, Probability and Reliability for Civil and Environmental Engineers, Mc Graw-Hill, 1997.

Regione Lombardia: SIRVAL, Sistema Informativo Regionale VALanghe (Regional Avalanche Information System), CDROM, 2002 (in Italian).

Salm, B., Burkard, A., and Gubler, H.: Berechnung von Fliesslawinen: eine Anleitung für Praktiker mit Beispielen [Avalanche calculations: a practical method with examples], Eidg. Inst. Schneeund Lawinenforsch. Mitt., 47, 41 pp., 1990 (in German). 